Journal of Management and Bussines (JOMB)

Volume 2, Nomor 2, Desember 2020

p-ISSN : 2656-8918

e-ISSN:2684-8317

DOI : https://doi.org/10.31539/jomb.v2i2.1529

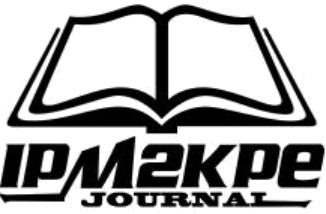

\title{
KEPUTUSAN PEMBELIAN MIE SEDAP GORENG BERDASARKAN KEMASAN DAN IKLAN MEDIA TELEVISI
}

\author{
Hestin \\ Sekolah Tinggi Ilmu Ekonomi Serelo Lahat \\ Hestin.stie@gmail.com
}

\begin{abstract}
ABSTRAK
Tujuan penelitian ini adalah untuk mengetahui pengaruh kemasan dan iklan media televisi terhadap keputusan pembelian Mie Sedap Goreng. Penelitian ini menggunakan metode asosiatif kuantitatif dengan sampel berjumlah 58 responden yang merupakan masyarakat Desa Wonorejo Kecamatan Kikim Barat yang membeli Mie Sedap Goreng. Hasil penelitian menunjukkan bahwa nilai thitung kemasan dan iklan media televisi masing-masing adalah 10,224 dan 2,247 $\left(>t_{\text {tabel }}=2,004\right)$. Adapun nilai $F_{\text {hitung kemasan }}$ dan iklan media televisi adalah 71,016 $\left(>\mathrm{F}_{\text {tabel }}=2,40\right)$ dengan nilai signifikansi $<$ taraf signifikansi $(0,000<0,05)$. Simpulan, kemasan dan iklan media televisi berpengaruh positif dan signifikan terhadap keputusan pembelian Mie Sedap Goreng. Kemudian secara simultan, kemasan dan iklan media televisi juga berpengaruh positif dan signifikan terhadap keputusan pembelian Mie Sedap Goreng.
\end{abstract}

Kata Kunci: Iklan Media Televisi, Kemasan, Keputusan Pembelian

\section{ABSTRACT}

The purpose of this study was to determine the effect of television media packaging and advertisements on the purchasing decision of Mie Sedap Goreng. This study used a quantitative associative method with a sample of 58 respondents who were the people of Wonorejo Village, Kikim Barat District who bought Mie Sedap Goreng. The results showed that the $t_{\text {count }}$ of packaging and television media advertisements were 10.224 and 2.247, respectively $\left(>t_{\text {table }}=2.004\right)$. The $F_{\text {count }}$ value of packaging and television media advertising is $71.016\left(>F_{\text {table }}=2.40\right)$ with a significance value < significance level $(0.000<0.05)$. In conclusion, packaging and television media advertisements have a positive and significant effect on the purchasing decision for Mie Sedap Goreng. Then simultaneously, television media packaging and advertisements also have a positive and significant effect on the purchasing decision for Mie Sedap Goreng.

Keywords: Television Media Advertising, Packaging, Purchasing Decisions

\section{PENDAHULUAN}

Dewasa ini perkembangan zaman semakin meningkat. Hal ini ditandai dengan kemajuan ilmu pengetahuan dan teknologi yang semakin modern dalam kehidupan sehari-hari. Kemajuan tersebut menyebabkan manusia modern terbiasa dengan segala sesuatu yang mudah dan cepat, termasuk dalam memenuhi kebutuhan pangan. Konsumen membutuhkan produk yang instan atau produk yang cepat dan mudah 
disajikan serta dapat dikonsumsi kapanpun dan dimanapun. Sifat kebutuhan konsumen seperti inilah yang membuat produk pangan dituntut untuk serba instan dan dapat memenuhi kebutuhan dan keinginan konsumen. Hal tersebut dapat mempengaruhi konsumen dalam menentukan keputusan pembelian produk. Mi instan adalah salah satu contoh produk yang paling tepat dalam memenuhi kebutuhan konsumen saat ini.

Kemajuan ilmu pengetahuan dan teknologi ini juga mengakibatkan persaingan produk mi instan di pasaran semakin ketat karena produsen mi instan saling berlombalomba dalam menciptakan produk yang sesuai dengan kebutuhan dan keinginan konsumen. Salah satu upaya produsen adalah dengan mendisain kemasan dan mempromosikan produknya melalui iklan pada media elektronik seperti televisi dengan harapan hal ini dapat mempengaruhi keputusan pembelian konsumen terhadap produk mi instan tersebut.

Promosi adalah kegiatan yang ditujukan untuk mempengaruhi konsumen agar mereka dapat menjadi kenal terhadap produk yang ditawarkan oleh perusahaan dan mereka menjadi senang lalu membeli produk tersebut (Gitosudarmo, 2013). Cara yang dapat dilakukan untuk memperkenalkan suatu produk adalah dengan mendesain kemasan dan memasukkan produk tersebut ke media iklan agar mudah dikenal oleh konsumen.

Kemasan menurut Kotler (2017) adalah bagian pertama produk yang terlihat oleh pembeli dan mampu menarik atau menyingkirkan pembeli. Kemasan juga mempengaruhi pengalaman produk. Kemasan yang dirancang dengan baik dapat membangun equitas merek dan mendorong penjualan. Salah satu media iklan yang biasa digunakan oleh pengusaha adalah media televisi (publisitas). Media ini dapat membentuk pengaruh secara langsung dan tidak langsung kepada konsumen agar mereka menjadi tahu dan menyenangi produk yg dipasarkan. Cara ini dapat dilakukan dengan memuat berita tentang produk atau perusahaan yang menghasilkan produk tersebut. Media massa lain yang dapat digunakan untuk iklan adalah surat kabar, radio, majalah tertentu dan lain-lain (Gitosudarmo, 2008).

Mie Sedap adalah merek mi instan yang diproduksi oleh Wings Food pada tahun 2003, tepatnya 31 tahun setelah Indomie. Mie Sedap memiliki berbagai varian rasa yang umumnya dibedakan menjadi dua yaitu mi goreng dan mie kuah. Untuk jenis mi goreng, Mie Sedap meproduksi beberapa varian rasa yaitu rasa sambal goreng, rasa sate, 
ayam spesial dan goreng kriuk. Sedangkan untuk jenis mi kuah, varian rasa Mie Sedap diantaranya yaitu rasa soto, rasa ayam bawang, kari ayam spesial dan white kari.

Produk mi instan yang sesuai dengan kebutuhan dan keinginan konsumen dapat dilihat dari sikap konsumen dalam mengonsumsi produk mi tersebut, diantaranya konsumen akan mempunyai pilihan yang mantap pada satu jenis produk mi instan yang dia sukai, kemudian konsumen akan mengkonsumsi produk mi instan tersebut secara berulang. Selain itu konsumen juga akan memberikan referensi, mengajak serta mempengaruhi konsumen lain untuk mengkonsumsi produk mi instan yang dia sukai. Oleh karena itu demi memenuhi keinginan dan harapan konsumen Mie Sedap Goreng, PT. Wings Food berusaha mengeluarkan produk Mie Sedap Goreng dengan semaksimal mungkin dengan cara mendesain kemasan dengan warna dasar putih dengan logo Mie Sedap yang terlihat jelas dan gambar sepiring mi goreng lengkap dengan ayam, telur dan bawang goreng yang terlihat begitu nikmat.

PT. Wings Food juga mengupayakan agar iklan yang disampaikan melalui media televisi dengan dibintangi oleh artis yang beradegan memperlihatkan bahwa artis tersebut sedang menyiapkan dan menikmati Mie Sedap Goreng tersebut secara instan dan dengan ekspresi yang menunjukkan bahwa Mie Sedap Goreng sangat enak. Kemasan dan iklan tersebut dibuat semenarik mungkin agar dapat menyampaikan pesan tentang produk tersebut serta dapat menumbuhkan dan mempengaruhi keputusan pembelian konsumen untuk membeli Mie Sedap Goreng. Meskipun demikian, usaha tersebut belum menjamin bahwa Mie Sedap Goreng sudah sesuai dengan kebutuhan dan keinginan konsumen.

Hasil observasi peneliti yang dilakukan pada masyarakat Desa Wonorejo menemukan bahwa kemasan Mie Sedap Goreng mudah rusak sehingga sering ditemukan mi yang melempam, bumbu yang sudah menggupal dan sering berceceran. Selain itu logo Mie Sedap juga cenderung monoton dengan warna dan bentuk yang ituitu saja, begitu pula dengan ukuran kemasan Mie Sedap Goreng yang hanya 9 gram. Dengan kata lain porsi Mie Sedap Goreng terlalu sedikit.

Menurut konsumen yang ada di Desa Wonorejo, iklan Mie Sedap Goreng yang ada di televisi memiliki durasi yang terlalu singkat serta jumlah tayang yang terlalu sedikit dan kebanyakan model iklan yang digunakan juga bukan merupakan figur atau tokoh yang populer dikalangan masyarakat. Selain itu jalan cerita iklan juga sering tidak 
jelas. Padahal dari sudut pandang perusahaan biaya yang dikeluarkan untuk pemasangan iklan melalui media televisi juga sangat mahal. Hal inilah yang menyebabkan konsumen Mie Sedap Goreng di Desa Wonorejo sering mengganti produk mi instan. Kebanyakan konsumen tidak melakukan pembelian ulang pada Mie Sedap Goreng. Selain itu konsumen Mie Sedap Goreng juga tidak mau memberikan informasi, mengajak, mempengaruhi orang lain untuk memilih Mie Sedap Goreng. Hal tersebut menunjukkan bahwa mi instan ini belum sesuai dengan harapan konsumen yang ada di Desa Wonorejo. Pendapat ini diperkuat oleh data penjualan Mie Sedap Goreng pada toko Engla pada tahun 2018 yang ditampilkan pada tabel berikut ini:

Tabel 1.

Data Penjualan Mie Sedap Goreng pada Toko Engla

Desa Wonorejo Tahun 2018

\begin{tabular}{ccc}
\hline No & Bulan & Penjualan / Bungkus \\
\hline 1. & Januari & 400 \\
2. & Februari & 600 \\
3. & Maret & 480 \\
4. & April & 560 \\
5. & Mei & 520 \\
6. & Juni & 420 \\
7. & Juli & 460 \\
8. & Agustus & 500 \\
9. & September & 380 \\
10. & Oktober & 400 \\
11. & November & 420 \\
12. & Desember & 440 \\
\hline & Jumlah & 5.580 \\
\hline
\end{tabular}

(Sumber: Toko Engla, 2019)

Berdasarkan tabel dan uraian di atas, peneliti tertarik untuk menganalisis hal-hal yang mempengaruhi keputusan konsumen dalam membeli mi instan seperti kemasan dan iklan media televisi serta seberapa besar pengaruhnya terhadap keputusan pembelian Mie Sedap Goreng di Desa Wonorejo.

\section{KAJIAN TEORI}

\section{Pengertian Keputusan Pembelian}

Menurut Sumarwan (2011) keputusan pembelian adalah keputusan konsumen mengenenai apa yang dibeli, apakah membeli atau tidak, kapan membeli, dimana membeli dan bagaimana cara membayarnya. Adapun menurut Dharmmesta (2013) keputusan pembelian adaah keputusan untuk membeli yang diambil oleh pembeli berdasarkan kumpulan dari sejumlah keputusan. Sedangkan menurut Kotler (2017) 
keputusan pembelian meliputi semua proses yang dilalui konsumen dalam mengenali masalah, mencari solusi, mengevaluasi alternatif dan memilih diantara pilihan-pilihan pembelian mereka. Kemudian keputusan pembelian menurut Nitisusastro (2012) adalah proses interaksi antara sikap afektif, sikap kognitif dan sikap behavioral dengan faktor lingkungan, dimana manusia melakukan pertukaran dalam semua aspek kehidupannya.

\section{Pengertian Kemasan}

Kemasan menurut Kotler (2017) adalah bagian pertama produk yang dihadapi pembeli dan mampu menarik atau menyingkirkan pembeli. Kemasan juga mempengaruhi pengalaman produk. Kemasan yang dirancang dengan baik dapat membangun ekuitas merk dan mendorong penjulan. Sedangkan menurut Tjiptono (2013) pengemasan (packaging) merupakan proses yang berkaitan dengan perancangan dan pembuatan wadah (cointainer) atau pembungkus (wrapper) untuk suatu produk.

Pemberian kemasan suatu produk bisa memberikan tiga manfaat utama yaitu: 1) manfaat komunikasi, manfaat utama kemasan adalah sebagai media pengungkapan informasi produk kepada konsumen, informasi tersebut meliputi cara penggunaan produk, komposisi produk dan informasi khusus; 2) manfaat fungsional, kemasan sering pula memastikan peranan fungsional yang penting seperti memberikan kemudahan, perlindungan dan penyimpanan; 3) manfaat perseptual, kemasan juga bermanfaat dalam menanamkan persepsi tertentu dalam benak konsumen. Dengan demikian dapat disimpulkan bahwa kemasan adalah suatu aktivitas yang dilakukan perusahaan untuk melindungi isi produk dimana kemasan tersebut sebagai identitas tersendiri dibanding produk yang lain.

\section{Pengertian Iklan}

Menurut Kotler \& Keller (2013) iklan adalah suatu proses komunikasi masa yang melibatkan sponsor tertentu atau pemasang iklan (pengiklan) yang membayar jasa sebuah media masa atas penyiaran iklannya. Komponen yang paling penting di dalam suatu iklan adalah pesan yang akan di sampaikan oleh iklan tersebut. Adapun menurut Kotler \& Amstrong (2014) keputusan adalah segala bentuk penyajian dan promosi ide barang atau jasa secara nonpersonal oleh suatu sponsor tertentu yang memerlukan pembayaran. 


\section{METODE PENELITIAN}

Penelitian ini menggunakan metode asosiatif kuantitatif. Menurut Sugiyono (2013) penelitian asosiatif kuantitatif adalah penelitian yang bertujuan untuk mengetahui derajat hubungan dan bentuk pengaruh antara dua variabel atau lebih, dimana dengan penelitian ini akan dibagun suatu teori yang berfungsi untuk menjelaskan, meramalkan dan mengontrol sesuatu. Penelitian ini dilakukan pada konsumen Mie Sedap Goreng Kriuk di Desa Wonorejo Kecamatan Kikim Barat. Penelitian ini dilakukan pada bulan Maret sampai Agustus 2018. Dalam penelitian ini akan dibahas pengaruh variabel kemasan dan variabel iklan media televisi terhadap keputusan pembelian.

\section{HASIL PENELITIAN}

\section{Uji Validitas}

Pengujian menggunakan uji dua sisi dengan taraf signifikansi 0,05. Kriteria pengujian kriteria pengujiannya adalah jika r-hitung $\geq$ r-tabel, maka instrumen atau item-item pernyataan berkorelasi signifikan terhadap skor total atau dinyatakan valid.

Jumlah data adalah $\mathrm{df}=58-2=56(\mathrm{df}=\mathrm{n}-2)$, maka didapat $\mathrm{r}_{\text {tabel }}$ sebesar 0,258. Setelah dilakukan pengujian validitas data pada kemasan dan iklan media televisi, semua item pernyataan dinyatakan valid. Begitu pula pada variabel keputusan pembelian semua item pernyataan juga dinyatakan valid. Hasil uji validitas untuk masing-masing variabel penelitian dapat dilihat pada tabel berikut ini:

Tabel 2.

Hasil Uji Validitas Variabel

Kemasan

\begin{tabular}{cccc}
\hline Item / Pernyataan Ke & r-Hitung & r-Tabel & Keterangan \\
\hline 1 & 0,781 & 0,258 & Valid \\
2 & 0,778 & 0,258 & Valid \\
3 & 0,659 & 0,258 & Valid \\
4 & 0,640 & 0,258 & Valid \\
\hline 5 & 0,663 & 0,258 & Valid \\
6 & 0,705 & 0,258 & Valid \\
7 & 0,608 & 0,258 & Valid \\
8 & 0,572 & 0,258 & Valid \\
\hline
\end{tabular}

(Sumber: Data Primer Diolah, 2019) 
Tabel 3.

Hasil Uji Validitas Variabel Iklan Media Televisi

\begin{tabular}{cccc}
\hline Item / Pernyataan Ke & r-Hitung & r-Tabel & Keterangan \\
\hline 1 & 0,726 & 0,258 & Valid \\
2 & 0,786 & 0,258 & Valid \\
3 & 0,732 & 0,258 & Valid \\
4 & 0,752 & 0,258 & Valid \\
5 & 0,672 & 0,258 & Valid \\
\hline 6 & 0,526 & 0,258 & Valid \\
7 & 0,729 & 0,258 & Valid \\
8 & 0,744 & 0,258 & Valid \\
9 & 0,680 & 0,258 & Valid \\
10 & 0,675 & 0,258 & Valid \\
\hline
\end{tabular}

(Sumber: Data Primer Diolah, 2019)

Tabel 4.

Hasil Uji Validitas Variabel

Keputusan Pembelian

\begin{tabular}{cccc}
\hline Item / Pernyataan Ke & r-Hitung & r-Tabel & Keterangan \\
\hline 1 & 0,850 & 0,258 & Valid \\
2 & 0,833 & 0,258 & Valid \\
3 & 0,820 & 0,258 & Valid \\
\hline 4 & 0,778 & 0,258 & Valid \\
5 & 0,741 & 0,258 & Valid \\
6 & 0,557 & 0,258 & Valid \\
\hline
\end{tabular}

(Sumber: Data Primer Diolah, 2019)

\section{Uji Reliabilitas}

Reliabilitas yang kurang dari 0,6 termasuk kategori kurang baik, sedangkan 0,7 dapat diterima dan di atas 0,8 adalah baik. Setelah uji validitas data untuk masingmasing variabel penelitian, semua item pernyataan valid dimasukkan ke dalam uji reliabilitas. Hasil uji reliabilitas dapat dilihat pada tabel 5.

Tabel 5.

Hasil Uji Reliabilitas

\begin{tabular}{lcc}
\hline \multicolumn{1}{c}{ Variabel } & Cronbanch's Alpha & Keterangan \\
\hline Kemasan & 0,828 & Reliabel \\
Iklan Media Televisi & 0,894 & Reliabel \\
Keputusan Pembelian & 0,859 & Reliabel \\
\hline
\end{tabular}

(Sumber: Data Primer Diolah, 2019) 


\section{Uji Normalitas}

Uji normalitas digunakan untuk mengetahui apakah populasi data berdistribusi normal atau tidak. Untuk mendeteksi normalitas data dapat dilihat melalui output grafik kurva normal p-plot. Suatu variabel dikatakan normal jika titik-titik data menyebar di sekitar garis diagonal dan penyebaran titik-titik data searah mengikuti garis diagonal.

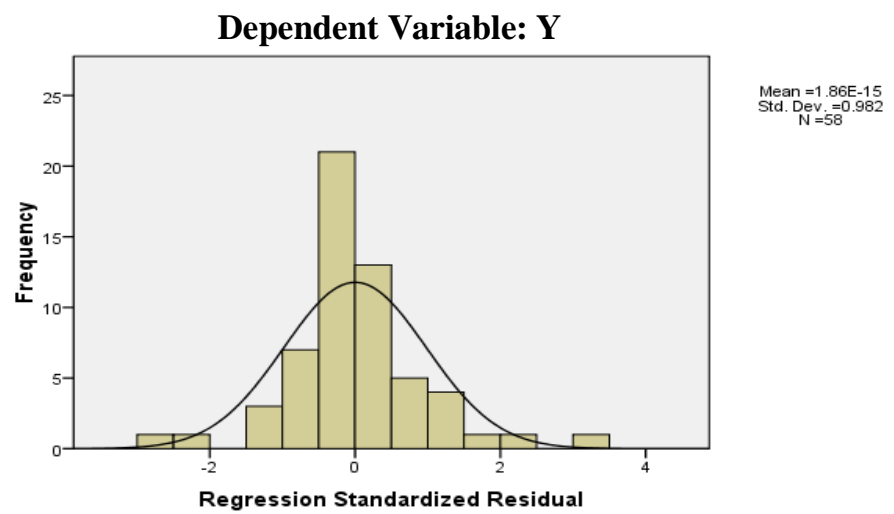

Gambar 1.

Grafik Histogram

(Sumber: Data Primer Diolah, 2019)

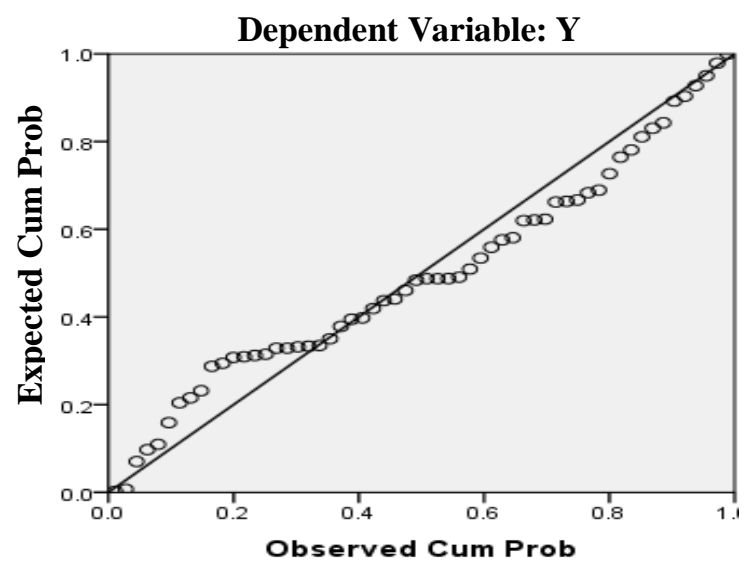

Gambar 2.

Grafik P-Plot

(Sumber: Data Primer Diolah, 2019)

Berdasarkan data gambar 1 dan 2, dapat diketahui bahwa grafik histogram memberikan pola distribusi yang melenceng ke kanan yang artinya adalah data berdistribusi normal. Adapun pada gambar P-Plot terlihat titik-titik mengikuti dan mendekati garis diagonalnya, sehingga dapat disimpulkan bahwa model regresi layak digunakan karena memenuhi asumsi normalitas. 


\section{Regresi Linier Berganda}

Analisis regresi linier berganda yang digunakan dalam penelitian ini bertujuan untuk mengetahui pengaruh kemasan dan iklan media televisi terhadap keputusan pembelian Mie Sedap Goreng serta pengaruh kemasan dan iklan media televisi secara simultan terhadap keputusan pembelian Mie Sedap Goreng di Desa Wonorejo Kecamatan Kikim Barat. Hasil analisis regresi linier berganda dapat dilihat pada tabel berikut ini:

Tabel 6.

Hasil Analisis Regresi Linier Berganda

\begin{tabular}{clc}
\hline No & \multicolumn{1}{c}{ Variabel } & Koefisien \\
\hline 1 & Konstanta & 1,819 \\
2 & Kemasan & 0,667 \\
3 & Iklan Media Televisi & 0,114 \\
\hline
\end{tabular}

(Sumber: Data Primer Diolah, 2019)

Berdasarkan hasil analisis tabel 6, peneliti memperoleh persamaan regresi linier berganda sebagai berikut:

$$
Y=1,819+0,667 X_{1}+0,114 X_{2}
$$

Persamaan regresi di atas dapat dijelaskan sebagai berikut: a) nilai konstanta adalah sebesar 1,819, artinya jika kemasan $\left(\mathrm{X}_{1}\right)$ dan iklan media televisi $\left(\mathrm{X}_{2}\right)$ adalah 0 , maka nilai keputusan pembelian (Y) adalah 1,819; b) koefisien regresi variabel kemasan $\left(\mathrm{X}_{1}\right)$ adalah sebesar 0,667, artinya jika kemasan mengalami kenaikan 1\%, maka keputusan pembelian (Y) akan mengalami peningkatan sebesar 0,667; c) koefisien regresi variabel iklan media televisi $\left(\mathrm{X}_{2}\right)$ adalah sebesar 0,114 , artinya jika iklan media televisi mengalami kenaikan 1\%, maka keputusan pembelian (Y) akan mengalami peningkatan sebesar 0,114 .

\section{Koefisien Determinasi}

Hasil analisis korelasi ganda dalam penelitian ini menunjukkan angka $\mathrm{R}$ sebesar 0,849, maka dapat disimpulkan bahwa terjadi hubungan yang kuat antara Kemasan Dan Iklan Media Televisiterhadap Keputusan Pembelian. Hasil analisis korelasi ganda (R) dapat dilihat pada tabel 7. 
Tabel 7.

Hasil Analisis Korelasi Ganda (R) dan Korelasi Determinan ( $\left.\mathrm{R}^{2}\right)$

\begin{tabular}{lcccc}
\hline \multicolumn{5}{c}{ Model Summary } \\
\hline Model & $\mathrm{R}$ & $\mathrm{R}$ Square & Adjusted $\mathrm{R}$ Square & Std. Error of the Estimate \\
\hline 1 & $.849^{\mathrm{a}}$ & .721 & .711 & 1.935 \\
\hline a. & Predictors: & (Constant), $\mathrm{X}_{2}, \mathrm{X}_{1}$ \\
b. & Dependent Variable: $\mathrm{Y}$ & & \\
\hline (Sumber: Data Primer Diolah, 2019)
\end{tabular}

Hasil analisis determinasi menunjukkan bahwa angka $\mathrm{R}^{2}$ ( $\mathrm{R}$ Square) adalah sebesar 0,711. Hal ini menunjukkan bahwa persentase sumbangan pengaruh variabel independen (kemasan dan iklan media televisi) terhadap variabel dependen (keputusan pembelian) adalah sebesar $71,1 \%$ atau variasi variabel independen yang digunakan dalam model mampu menjelaskan $71,1 \%$ variabel dependen. Adapun sisanya sebesar 28,9\% dipengaruhi atau dijelaskan oleh variabel lain yang tidak dimasukkan dalam model penelitian ini.

\section{Uji Parsial (Uji t)}

\section{Uji t Kemasan $\left(\mathbf{X}_{1}\right)$ dengan Keputusan Pembelian (Y)}

Tabel 8.

Hasil Uji t

\begin{tabular}{|c|c|c|c|c|c|c|}
\hline \multicolumn{7}{|c|}{ Coefficients $^{a}$} \\
\hline & & $\begin{array}{r}\text { Unst } \\
\text { Co }\end{array}$ & $\begin{array}{l}\text { Irdized } \\
\text { ients }\end{array}$ & $\begin{array}{c}\text { Standardized } \\
\text { Coefficients }\end{array}$ & $\mathrm{T}$ & Sig. \\
\hline \multicolumn{2}{|c|}{ Model } & B & Std. Error & Beta & & \\
\hline \multirow[t]{3}{*}{1} & (Constant) & 1.819 & 2.396 & & .759 & .051 \\
\hline & $X_{1}$ & .667 & .065 & .775 & 10.224 & .000 \\
\hline & $X_{2}$ & .114 & .051 & .170 & 2.247 & .002 \\
\hline
\end{tabular}

(Sumber: Data Primer Diolah, 2019)

Berdasarkan tabel 8, nilai thitung untuk variabel kemasan adalah sebesar 10,224 dengan nilai $t_{\text {tabel }}$ yaitu sebesar 2,004. Selain itu nilai signifikansinya adalah sebesar 0,000 lebih kecil daripada taraf signifikansi $(\alpha)$ 0,05. Karena nilai $t_{\text {hitung }}>t_{\text {tabel, }}$, maka hal tersebut menunjukkan bahwa kemasan berpengaruh positif dan signifikan terhadap keputusan pembelian. 
Uji t Iklan Media Televisi ( $\left.\mathbf{X}_{2}\right)$ dengan Keputusan Pembelian (Y)

Tabel 9.

Hasil Uji t

\begin{tabular}{|c|c|c|c|c|c|c|}
\hline \multicolumn{7}{|c|}{ Coefficients $^{a}$} \\
\hline & & Unstand & d Coefficients & Standardized Coefficients & & \\
\hline \multicolumn{2}{|c|}{ Model } & $\mathrm{B}$ & Std. Error & Beta & $\mathrm{t}$ & Sig. \\
\hline \multirow[t]{3}{*}{1} & (Constant) & 1.819 & 2.396 & & .759 & .051 \\
\hline & $\mathrm{X}_{1}$ & .667 & .065 & .775 & 10.224 & .000 \\
\hline & $\mathrm{X}_{2}$ & .114 & .051 & .170 & 2.247 & .002 \\
\hline
\end{tabular}

(Sumber: Data Primer Diolah, 2019)

Berdasarkan tabel 9, dapat diketahui bahwa nilai thitung untuk variabel iklan media televisi adalah sebesar 2,247 dengan nilai $t_{\text {tabel }}$ yaitu sebesar 2,004. Selain itu nilai signifikansi variabel ini adalah sebesar 0,002 $(<0,05)$. Hal tersebut membuktikan bahwa iklan media televisi berpengaruh positif dan signifikan terhadap keputusan pembelian.

\section{Uji Simultan (Uji F)}

Tabel 10.

Hasil Uji F

\begin{tabular}{|c|c|c|c|c|c|c|}
\hline \multicolumn{7}{|c|}{ ANOVA $^{\mathrm{b}}$} \\
\hline \multicolumn{2}{|c|}{ Model } & Sum of Squares & df & Mean Square & $\mathrm{F}$ & Sig. \\
\hline \multirow[t]{3}{*}{1} & Regression & 531.694 & 2 & 265.847 & 71.016 & $.000^{\mathrm{a}}$ \\
\hline & Residual & 205.893 & 55 & 3.744 & & \\
\hline & Total & 737.586 & 57 & & & \\
\hline \multicolumn{7}{|c|}{ a. Predictors: (Constant), $\mathrm{X}_{2}, \mathrm{X}_{1}$} \\
\hline \multicolumn{7}{|c|}{ b. Dependent Variable: Y } \\
\hline
\end{tabular}

Berdasarkan tabel 10 , nilai $\mathrm{F}_{\text {hitung }}$ adalah sebesar 71,016 , sedangkan nilai $\mathrm{F}_{\text {tabel }}$ adalah sebesar 2,40 (df $(1)=3-1=2$ dan df $(2)=58-2-1=55)$. Selain itu nilai signifikansinya adalah sebesar $0,000 \quad(<0,05)$. Hal tersebut menunjukkan bahwa kemasan dan iklan media televisi secara simultan berpengaruh positif dan signifikan terhadap keputusan pembelian. 


\section{PEMBAHASAN}

Menurut Kotler \& Amstrong (2014) kemasan adalah proses yang melibatkan kegiatan mendesain dan memproduksi. Fungsi utama dari kemasan sendiri yaitu untuk melindungi produk agar produk tetap terjaga kualitasnya. Fungsi lainnya adalah untuk mengkomunikasikan produk melalui informasi yang tertera dalam desain kemasan. Informasi tersebut dapat membantu konsumen dalam membuat keputusan pembelian dengan lebih hati-hati (Silayoi \& Speece, 2005). Desain kemasan juga termasuk salah satu faktor penting dalam penjualan produk. Jika bentuk dan bahan kemasan telah memenuhi standar, maka elemen grafis pada kemasan dapat menjadi faktor penentu menarik atau tidaknya sebuah kemasan. Kelebihan desain kemasan yang sangat diperhatikan oleh konsumen sebagai bahan pertimbangan mereka dalam melakukan keputusan pembelian adalah sebagai berikut: 1) ukuran dan bentuk dari kemasan; 2) bahan dari kemasan; 3) warna dari kemasan suatu produk; 4) merek dan label yang terdapat pada kemasan (Dhameria, 2014).

Faktor yang tidak kalah penting dalam mempengaruhi keputusan komsumen untuk melakukan pembelian suatu produk adalah iklan media televisi. Iklan di televisi merupakan bentuk iklan yang paling mudah diakses dan paling berpengaruh karena media ini berada pada tingkat konsumsi media yang paling tinggi di Indonesia. Hal tersebut menunjukkan bahwa kegiatan promosi melalui media televisi merupakan cara yang tepat untuk menarik perhatian penonton dengan memperkenalkan produk yang diiklankan (Winata \& Nurcahya, 2017). Iklan yang ditayangkan pada media televisi dapat menjadi alternatif pilihan yang menarik karena jangkauan televisi yang luas. Unsur hiburan yang terdapat pada iklan dapat memicu timbulnya keinginan dari konsumen untuk mencoba suatu produk yang pada akhirnya dapat mengarah pada keputusan konsumen dalam melakukan pembelian (Komaryatin, 2009).

Keputusan untuk membeli timbul karena adanya penilaian yang objektif atau dorongan emosi. Keputusan untuk bertindak adalah hasil dari serangkaian aktivitas dan rangsangan mental serta emosional (Darmawan, 2017). Sebuah keputusan pembelian memiliki beberapa peran konsumen yaitu sebagai inisiator, influencer, decider, buyer dan user. Perusahaan harus mengenal peranan tersebut karena semua peranan mengandung implikasi yang dibutuhkan oleh perusahaan guna merancang produk, menentukan pesan dan mengalokasikan biaya anggaran promosi serta membuat 
program pemasaran yang sesuai dengan keinginan pembeli (Dharmmesta \& Handoko, 2011).

Hasil yang diperoleh pada penelitian ini menunjukkan bahwa kemasan dan iklan media televisi berpengaruh terhadap keputusan masyarakat Desa Wonorejo Kecamatan Kikim Barat untuk melakukan pembelian Mie Sedap Goreng. Menurut Darmawan (2017) kemasan berpengaruh signifikan secara parsial dan simultan terhadap keputusan pembelian. Hasil ini membuktikan bahwa para konsumen mempertimbangkan variabel kemasan untuk melakukan pembelian. Selain kemasan, menurut Winata \& Nurcahya (2017), iklan juga sangat menentukan keputusan konsumen dalam melakukan pembelian. Semua aspek dalam iklan yang terdiri dari pesan iklan, musik iklan, ilustrasi cerita dan bintang iklan sangat berpengaruh positif dan signifikan terhadap minat beli konsumen.

\section{SIMPULAN}

Kemasan dan iklan media televisi berpengaruh sebesar $71,1 \%$ terhadap keputusan pembelian, sedangkan sisanya sebesar $28,9 \%$ dipengaruhi atau dijelaskan oleh variabel lain yang tidak dimasukkan dalam model penelitian ini.

Secara parsial, hasil menunjukkan bahwa kemasan dan iklan media televisi berpengaruh positif dan signifikan terhadap keputusan pembelian. Adapun secara simultan, hasil menunjukkan bahwa kemasan dan iklan media televisi memiliki pengaruh yang positif dan signifikan terhadap keputusan pembelian.

\section{DAFTAR PUSTAKA}

Darmawan, D. (2017). Pengaruh Kemasan dan Harga terhadap Keputusan Pembelian Produk Sayuran Hidroponik. Agrimas, 1(1), 1-10

Dhameria, V. (2014). Analisis Pengaruh Keunikan Desain Kemasan Produk, Kondusivitas Store Environment, Kualitas Display Produk terhadap Keputusan Pembelian Impulsif (Studi pada Pasaraya Sri Ratu Pemuda Semarang). Jurnal Sains Pemasaran Indonesia, 8(1), 1-44

Dharmmesta, B. S. (2013). Manajemen Pemasaran. Yogyakarta: BPEE

Dharmmesta, B. S., \& Handoko, T. H. (2011). Manajemen Pemasaran: Analisis Perilaku Konsumen, Edisi Keenam. Yogyakarta: BPFE

Gitosudarmo, I. (2008). Manajemen Pemasaran, Edisi Kedua, Cetakan Keenam. Yogyakarta: BPFE

Gitosudarmo, I. (2013). Manajemen Pemasaran. Yogyakarta: BPEE 
Komaryatin, N. (2009). Pengaruh Iklan Media Televisi dan Atribut Produk terhadap Keputusan Konsumen untuk Melakukan Pembelian. Jurnal Dinamika Ekonomi dan Bisnis, 6(2), 137-144

Kotler, P. (2017). Manajemen Pemasaran. Jakarta: PT. Prehalindo

Kotler, P., \& Amstrong, G. (2014). Principles of Marketing, 12th Edition, Jilid 1, Diterjemahkan: Bob Sabran. Jakarta : Erlangga

Kotler, P., \& Keller, K. L. (2013). Manajemen Pemasaran, Jilid Kedua. Jakarta: Erlangga

Nitisusastro, M. (2012). Perilaku Konsumen. Bandung: Alfabeta

Silayoi, P., \& Speece, M. (2005). The Importance of Packaging Attributes: A Conjoint Analysis Approach. European Journal of Marketing, 41(11/12), 1495-1517

Sugiyono, S. (2013). Metode Penelitian Pendidikan Pendekatan Kuantitatif, Kualitatif, dan R\&D. Bandung: Alfabeta

Sumarwan, U. (2011). Prilaku Konsumen. Bogor: PT.Ghahalia Indonesia

Tjiptono, T. (2013). Manajemen pemasaran. Yogyakarta: CAPS

Winata, A., \& Nurcahya, I. K. (2017). Pengaruh Iklan pada Media Televisi terhadap Minat Beli (Studi pada Calon Konsumen Bukalapak.com di Kota Denpasar). EJurnal Manajemen Unud, 6(10), 5660-5692 